\section{Biologia Futura}

https://akademiai.com/loi/019

\section{Original Article}

Cite this article: Abdennour $\mathrm{S}$, Houcine B, Rhouma S, Sahbi F, and Tahar S. 2019. Stability and adaptability concepts of bread wheat (Triticum aestivum L.) in the northwest of Tunisia. Biol. Fut. 70, 240-250.

Received: 15 February 2019

Accepted: 25 August 2019

\section{Keywords:}

bread wheat, genotype, environments, interaction, adaptability, stability

\section{Stability and adaptability concepts of bread wheat (Triticum aestivum $\mathrm{L}$.) in the northwest of Tunisia}

\author{
Sebei Abdennour ${ }^{1}$, Bchini Houcine ${ }^{1}$, Sayar Rhouma ${ }^{2}$, \\ Ferjaoui Sahbi ${ }^{1}$ and Sghaier Tahar ${ }^{3}$ \\ ${ }^{1}$ Field Crops Laboratory (INRAT), Regional Field Crops Research Center of Beja (CRRGCB), \\ University of Carthage, $5 \mathrm{~km}$, Route de Tunis, 9000 Béja, Tunisia \\ ${ }^{2}$ Higher School of Agriculture of Kef (ESAK), Jendouba University, Kef, Tunisia \\ ${ }^{3}$ National Institute of Research in Rural Engineering, Water and Forests (INREGREF), Ariana, \\ Tunisia
}

DOI: $10.1556 / 019.70 .2019 .28$

Introduction: Stability and adaptability of 25 bread wheat (Triticum aestivum L.) cultivars were evaluated for genotype $\times$ environment interaction $(\mathrm{G} \times \mathrm{E})$ and yield stability across two environments over 2 years (2014 and 2015). Materials and methods: Five improved varieties (Haidra, Salammbô, Tahent, Utique, and Vagua) released in Tunisia and 20 introduced genotypes (V1-V20) have been tested under two contrasted environments during 2 years characterized by different precipitations in the northwest of Tunisia. Several statistical approaches were conducted to evaluate yield stability: (a) regression coefficient $\left(b_{i}\right)$, (b) deviation from regression $\left(S_{d i}\right)$, (c) ecovalence $\left(W_{i}\right)$, (d) Hühn stability $\left(S_{l i}\right)$, and (e) AMMI stability value. Results: A standard multifactor analysis of variance test showed that the main effects due to genotypes, locations, and the interaction (genotype $\times$ locations) were highly significant. The highly significant interactions indicate that genotypes need to be tested during several years and at different locations for selecting the most stable one. The results showed that all statistical analyses allowed classifying the 25 studied genotypes according to their grain yield level (low, medium, or high), their adaptability to different environments. Conclusion: Tahent variety was confirmed to be most valuable due to its high production level, stability and its adaptability to variable environments including unfavorable ones.

\section{INTRODUCTION}

The considerable variation in soil and climate explains the significant annual variation in yield performance of bread wheat (Triticum aestivum L.) (BW) varieties. Thus, genotype $\times$ environment interaction $(\mathrm{G} \times \mathrm{E})$ is an important issue faced by plant breeders and agronomists in Tunisia. In assessing the performance of BW genotypes in the northwest of Tunisia, it is essential that the yield stability of such genotypes, in addition to their yield performance, was determined to make specific selections and recommendations to $\mathrm{BW}$ producers.

Measuring $G \times E$ helps to determine an optimum breeding strategy, to breed for specific or wide adaptation, which depends on the expression of stability under a limited or wide range (Crossa, 1990; Romagosa \& Fox, 1993).

The main cause of differences among genotypes in their yield stability is the occurrence of $\mathrm{G} \times \mathrm{E}$. The yield, for a given genotype, varies from an environment to another. This variation is the result of $\mathrm{G} \times \mathrm{E}$. Because of these important variations, yield stability is an important criterion for the development of a new released variety. Phenotypic stability, yield stability, and adaptation or adaptability are the most often used terms sometimes with different meanings. The absence of a single definition is due to the fact that, when analyzing the $G \times E$, only a part of the variation of the interactions can be explained by the methods of decomposing the interaction.

Frequent biotic and abiotic stresses throughout the years and locations affect BW kernel yield stability (Chamekh et al., 2015). Water stress and high spring temperatures, typical of the southern areas of the Mediterranean basin, directly threaten the grain yield (GY) of BW crops (Loss \& Siddique, 1994). 
To mitigate the effect of these repeated stresses during the end of the vegetative cycle, additional efforts are needed to select more productive genotypes with good yield stability across a broad range of environmental conditions (Subira et al., 2015). Multilocation trials play an important role in plant breeding and agronomic research. Such trials have three main objectives: (a) to accurately estimate and predict yield based on limited experimental data, (b) to determine yield stability and the pattern of response of genotypes across environments, and (c) to provide reliable guidance for selecting the best genotypes or agronomic treatments for planting in future years and at new sites (Crossa, 1990).

A variety is considered stable when it shows small fluctuations across different environments (Purchase, 1997). Indeed, Brancourt-Hulmel et al. (1997) reported that stability may be due to the presence of specific genes. Stability characterizes the importance of the fluctuations of an observed trait (e.g., the yield) for the same genotype cultivated in different sites. The most stable genotypes show the least phenotypic variation (Brancourt-Hulmel et al., 1997).

The $\mathrm{G} \times \mathrm{E}$ represents the quantitative and qualitative variation, among various environments and differences between genotypes. Interaction disrupts the association that can be made between phenotypic value and genotypic value of a trait (Preece, 1997). It is the $\mathrm{G} \times \mathrm{E}$, which makes it possible to explain that certain genotypes are more efficient than others for a specific type of environment. Indeed, Nachit et al. (1992) and Khan et al. (2007) reported that the $\mathrm{G} \times \mathrm{E}$ study provided indices for the selection of genotypes with wide or specific adaptation.

A number of parametric statistical procedures have been developed to analyze $\mathrm{G} \times \mathrm{E}$ and especially yield stability across locations. A number of different approaches, such as joint regression analysis and multivariate statistics, have been used to describe the performance of genotypes in different environments. To date, considerable differences of opinion still exist between the leading protagonists of the different statistical approaches as the best and most suitable procedure to be used for a specific data set or production region.

This study aimed to determine the best suitable stability analyses for BW in the northwest of Tunisia and also discuss some statistical and biological limitations. In addition, this study is based on the decomposition of the $\mathrm{G} \times \mathrm{E}$ according to different approaches. The advantages and disadvantages of these approaches have been discussed by Fikere et al. (2014).

The objectives of this research were to study and compare the various statistical methods of analysis with new statistical approaches to evaluate and describe $25 \mathrm{BW}$ genotypes performance across four dry land locations(multi location trials), to determine the most suitable method for a wide range of BW genotypes at BW producing areas of Tunisia, and to assess new Tunisian BW genotypes for adaptation using multivariate statistical analysis [additive main effect and multiplicative interaction (AMMI)].

\section{MATERIALS AND METHODS}

\section{Plant material}

A total of 25 varieties and promising genotypes of BW (Triticum aestivum L.) listed in Table 1 were evaluated for
Table 1. Pedigree of the 25 bread wheat genotypes used in the study

\begin{tabular}{|c|c|c|}
\hline Entry & Code & Pedigree \\
\hline 1 & V1 & $\begin{array}{l}\text { WW1102 ND/VG9144//Cal/Bb/3/YACO/ } \\
\text { 4/Vee\#5 }\end{array}$ \\
\hline 2 & $\mathrm{~V} 2$ & $\begin{array}{l}\text { ROLF07*2/4/CROC_1/ } \\
\text { AE.SQUARROSA(205) }\end{array}$ \\
\hline 3 & V3 & UP2338*2/KKTS*2//YANAC \\
\hline 4 & V4 & WAXWING*2/KUTONA \\
\hline 5 & V5 & $\begin{array}{l}\text { CROC1/AE.SQUARROSA(205)// } \\
\text { BORL95/3/2*MILAN }\end{array}$ \\
\hline 6 & V6 & $\begin{array}{l}\text { ALTAR84/AE.SQUARROSA (221)// } \\
3 * \text { BORL95 }\end{array}$ \\
\hline 7 & V7 & V79391/Vee5 "S"//Tow "S"/Pew "S" \\
\hline 8 & V8 & SOKOLL/TROST \\
\hline 9 & V9 & WBLL1*2/KURUKU//HEILO \\
\hline 10 & V10 & $\begin{array}{l}\text { Kachu \#1/4/CROC_1/Ae. Squarrosa } \\
(205) / / \text { Kauz }\end{array}$ \\
\hline 11 & V11 & TILHI/PASTOR \\
\hline 12 & V12 & $\begin{array}{l}\text { MILAN/KAUZ//PRINIA/3/BAV92/4/ } \\
\text { ATTILA/BAV92 }\end{array}$ \\
\hline 13 & V13 & BERKUT \\
\hline 14 & V14 & WHEAR/KRONSTAD F2004 \\
\hline 15 & V15 & $\begin{array}{l}\text { CN079//PF70354/MUS/3/PASTOR/4/ } \\
\text { BAV92*2 }\end{array}$ \\
\hline 16 & V16 & $\begin{array}{l}\text { VORB/4/D67.2/PARANA66.270// } \\
\text { AE.SQUARROSA(32 ... }\end{array}$ \\
\hline 17 & V17 & OASIS / SKAUZ//4*BCN /3/ $2 *$ PASTOR \\
\hline 18 & V18 & $\begin{array}{l}\text { A93324S.7197.29/4 /KAUZ //ALTAR84 } \\
\text { /AOS /3/KAUZ/ . }\end{array}$ \\
\hline 19 & V19 & $\begin{array}{l}\text { BABAX/3/OASIS/SKAUZ//4*BCN/4/ } \\
\text { PASTEUR }\end{array}$ \\
\hline 20 & V20 & ATTILA/3*BCN//BAV92/3/TILHI \\
\hline 21 & Tahent & $\begin{array}{l}\text { ATTILA/3/HUI/CARC//CHEN/CHTO/4/ } \\
\text { ATTILA }\end{array}$ \\
\hline 22 & Haidra & Bow "S"/Dougga \\
\hline 23 & Utique & ND/VG 9144//Kal/Bb/3/Yaco/4/Vee\#5 \\
\hline 24 & Salammbô & Pato//Corre Camminos/Inia \\
\hline 25 & Vagua & $\begin{array}{l}\text { 47778*2//Fkm/Gb/3/Vee\#5/4/Buc“S”/ } \\
\text { Pun“S” }\end{array}$ \\
\hline
\end{tabular}

two consecutive years. Study was carried out at two different locations in the northwest of Tunisia during (2013/2014) and (2014/2015) cropping seasons, under rainfed conditions.

Management and fertilization at each site were performed according to the practices of each specific field. Fertilization rates with planting were inflated with about $15 \%$ to insure good and even stands and development.

\section{Experimental sites}

Evaluation of agronomic performance traits and records of physiological parameters were carried out at two research stations in Tunisia at Oued Beja and Oued Mliz.

Stability evaluation was conducted in four environments (E1: Oued Mliz 2014, E2: Oued Mliz 2015, E3: Oued Beja 2014, and E4: Oued Beja 2015), which were spread throughout the major BW growing areas of Tunisia. Monthly rainfall is presented in Supplementary Fig. S1. Coordinates and physicochemical characteristics of sites are listed in Table 2. 
Table 2. Geographical and physicochemical characteristics of the two experimental sites

\begin{tabular}{lcc}
\hline & \multicolumn{2}{c}{ Environments } \\
\cline { 2 - 3 } Characteristics & $\begin{array}{c}\text { Oued Mliz } \\
(\text { E1 and E2) }\end{array}$ & $\begin{array}{c}\text { Oued Beja } \\
\text { (E3 and E4) }\end{array}$ \\
\hline Longitude & $6^{\circ} 76^{\prime} \mathrm{E}$ & $9^{\circ} 12^{\prime} \mathrm{E}$ \\
Latitude & $40^{\circ} 50^{\prime} \mathrm{N}$ & $36^{\circ} 43^{\prime} \mathrm{N}$ \\
Altitude (m) & 195 & 161 \\
Sol type & Vertic xero crept & Vertic \\
pH & 7.4 & 7 \\
Clay (\%) & 30 & $50-70$ \\
Organic matter $(\%)$ & $3-4$ & $1.6-2$ \\
Annual average & 451 & 560 \\
precipitation (mm) & & \\
Temperature colder & 9.8 & 10 \\
month $\left({ }^{\circ} \mathrm{C}\right)$ & & \\
Bioclimatic zone & Semi-arid & Subhumid \\
PET (mm/year) & $1,200-1,400$ & $80-1,200$ \\
\hline
\end{tabular}

Note. Monthly rainfall recorded at all locations during both surveys is shown in Fig. 1. PT: potential evapotranspiration.

\section{Experimental design}

Multisite trials are used to evaluate the performance of stability in space, whereas multiyear trials evaluate performance over time. Frequently, the evaluation is very hard because the trials are both multi-local and multi-year to take into account these two components of stability. Used experimental layout was a randomized complete block design with three replications within years. Trials were planted according to the practices of the nearest research station.

Experimental trials are conducted according to the same crop system. BW trials were installed after a food legume crop. Experimental fields were plowed the first week of November. Seeding was carried out in mid-November on elementary plots of $6 \mathrm{~m}^{2}$.

\section{Measured variables}

During the growing season, a number of agronomic and physiological traits were recorded. For both locations, duration of the vegetative period (from sowing to anthesis) according to Zadok's scale (Zadoks et al., 1974), reproductive period, grain filling period, duration of physiological maturity (PM; 89 on the Zadok's scale), biological yield (BY: $\mathrm{t} / \mathrm{ha})$, and GY $\left(\mathrm{g} / \mathrm{m}^{2}\right.$, which was the only parameter used for the stability analysis) was measured at maturity, and harvest index (HI) was calculated as the quotient between GY and BY. Plant height (PH) was measured in $\mathrm{cm}$ at maturity from five randomly selected plants within each plot and recorded as the distance in centimeters from soil level to the tip of spikes excluding the awns. Spike length recorded in $\mathrm{cm}$ as the average of 10 representative spikes of each plot from the base up to the tip of the spike. Each of these spikes then threshed individually and the average grain yields/ear per spike, expressed in grams, and number (KNS) for each of the entries were also recorded.

\section{Statistical analyses}

A combined analysis of variance was carried out from the mean data from each location, to create the means data for the different statistical analyses methods. Statistical analysis was performed using GLM, REG, and PRINCOMP procedures of SAS/STAT (SAS, 2004).

The analysis of variance of the combined data expresses the observed $\left(Y_{i j}\right)$ mean yield of the $i^{\text {th }}$ genotype at the $j^{\text {th }}$ environment as

$$
Y_{i j}=\mu+G_{i}+E_{j}+G E_{i j}+e_{i j}
$$

where $\mu$ is the general mean; $G_{i}, E_{j}$, and $G E_{i j}$ represent the effect of the genotype, environment, and the $\mathrm{G} \times \mathrm{E}$, respectively; and $\mathrm{e}_{i j}$ is the average of the random errors associated with the $r^{\text {th }}$ plot that receives the $i^{\text {th }}$ genotype in the $j^{\text {th }}$ environment.

This no-additive interaction implies that the expected value of the $i^{\text {th }}$ genotype in the $j^{\text {th }}$ environment $\left(Y_{i j}\right)$ depends not only on the levels of $\mathrm{G}$ and separately but also on the particular combination of levels of $\mathrm{G}$ and $\mathrm{E}$.

\section{Stability analysis approaches}

Joint regression analysis (JRA). JRA is a model used for analyzing and interpreting the no additive structure (interaction) of two-way classification data. The $\mathrm{G} \times \mathrm{E}$ is partitioned into a component due to linear regression $\left(b_{i}\right)$ of the $i^{\text {th }}$ genotype on the environment mean, and a deviation $\left(d_{i j}\right)$. Therefore, the classical model of simple linear regression used is:

$$
\bar{Y}_{i j}=a_{i}+b_{i} x_{j}+d_{i j}
$$

Knowing that the variable $x_{j}$, called the environmental index, is defined as follows:

$$
x_{j}=\bar{Y}_{j}-\bar{Y} \ldots
$$

This gives rise to the following property and estimates:

$$
\begin{aligned}
\sum_{j=1}^{q} x_{j} & =0 \\
b_{i} & =\left[\sum_{j=1}^{q}\left(\bar{Y}_{i j .} x_{j}\right)\right] / \sum_{j=1}^{q} x_{j}^{2}, \\
a_{i} & =\bar{Y}_{i . .}-b_{i} \bar{x}_{j}=\bar{Y}_{i . .} .
\end{aligned}
$$

The regression coefficient $\left(b_{i}\right)$, called parameter of adaptability to different conditions of the environment, is considered as an index expressing the stability of the variety $i$ to different environment $j$. The $b_{i}$ value close to 1.0 indicates a variety adapted to all environment (wide adaptation). A regression coefficient above 1.0 indicates a variety specifically adapted to favorable environment. However, the value of $b_{i}$ below 1.0 indicates a variety specifically adapted to unfavorable environments. 
As for the term $d_{i j}$, as follows:

$$
d_{i j .}=\left(\bar{Y}_{i j .}-\widehat{Y}_{i j .}\right)
$$

Knowing that $\hat{Y}_{i j}$ is the model estimated of the average performance of the variety $i$ for the environment $j$. These residues are used to calculate a residual standard deviation per variety $I$, which is written as follows:

$$
d_{i}=\sqrt{\left(\sum_{j=1}^{q} d_{i j}^{2}\right) /(q-2)} .
$$

Wricke's ecovalence $\left(W_{i}\right)$. The $W_{i}$ or stability of the $i^{\text {th }}$ genotype is its interaction with the environments, squared and summed across environments, and expressed as

$$
W_{i}=\sum_{j=1}^{q}\left(\bar{Y}_{i j .}-\bar{Y}_{i . .}-\bar{Y}_{. j .}+\bar{Y}_{\ldots}\right)^{2}=\sum_{j=1}^{q} I_{i j}^{2},
$$

where $\bar{Y}_{i j}$ is the mean performance of genotype $i$ in the $j^{\text {th }}$ environment. $\bar{Y}_{i}$ and $\bar{Y}_{j}$. are the genotype and environment mean deviations, respectively. $Y$.. is the overall mean. For this reason, genotypes with a low $W_{i}$ value have smaller deviations from the mean across environments and are thus more stable.

As for the average ecovalence for variety $i$, it is defined as follows:

$$
W_{i}^{\prime}=\frac{1}{n_{i . .}} \sum_{j=1}^{q} n_{i j} I_{i j}^{2}
$$

where $n_{i . .}$ denotes number of varieties.

This individual ecovalence can be further expressed in the following way:

$$
W_{i}^{\prime \prime}=\frac{W_{i}^{\prime}}{\sum_{i=1}^{p} W_{i}^{\prime}} \times 100 .
$$

Hühn stability or Hühn's mean absolute rank difference $\left(S_{l i}\right)$. The Hühn's mean absolute rank difference $\left(S_{l i}\right)$ estimates are all possible pair-wise rank differences across locations for each genotype and are defined as:

$$
S_{l i}=\frac{2 \sum_{j>j^{\prime}}\left|r_{i j}-r_{i j^{\prime}}\right|}{q(q-1)} .
$$

AMMI stability value (ASV). The AMMI model does not make provision for a quantitative stability measure; such a measure is essential to quantify and rank genotypes according yield stability. AMMI approach to study $\mathrm{G} \times \mathrm{E}$ consists in performing a principal component analysis $(\mathrm{PCA}=\mathrm{ACP})$ on the genotypes interaction values $\left(I_{i j}\right)$ in different environments

$$
I_{i j}=\bar{Y}_{i j .}-\bar{Y}_{i . .}-\bar{Y}_{. j .}+\bar{Y}_{\text {. }}
$$

The AMMI model of variance analysis can be written in the following form:

$$
Y_{i j k}=m+v_{i}+e_{j}+\sum_{l=1}^{n} \lambda_{l} \alpha_{i l} \gamma_{j l}+D_{i j k},
$$

$m$ : overall average,

$v_{i}$ : effect of variety $I$,

$e_{j}$ : effect of environment $j$,

$D_{i j k}$ : residuals of zero mean and the same variance,

$\lambda_{l}: l$ axis value of the ACP,

$\alpha_{i l}: i$ variety vector relating to $l$ axis of the ACP,

$\gamma_{j l}: j$ environment vector relating to $l$ axis of the ACP, $n$ : number of ACP main axis retained in the model.

Vectors $\alpha_{i 1}$ and $\gamma_{j 1}$ must be normalized (their sums squares are equal to unity) to satisfy this condition:

For every axis $i: \quad \sum_{i=1}^{p} \alpha_{i l}^{\prime 2}=\sum_{j=1}^{q} \gamma_{j l}^{\prime 2}=1$ with: $\alpha_{i l}^{\prime}=\frac{\alpha_{i l}}{\sqrt{\sum_{i=1}^{p} \alpha_{i l}^{2}}}$ and $\gamma_{j l}^{\prime}=\frac{\gamma_{j l}}{\sqrt{\sum_{j=1}^{q} \gamma_{j l}^{2}}}$.

Scores of varieties and environments on the main axes selected for the study of the interaction are calculated as follows:

For every variety $i: \operatorname{ACPI}_{i l(\text { score })}=\alpha_{i l}^{\prime} \sqrt{\lambda_{l}}$.

For every environment $j$ : ACPI $j l($ Score $)=\gamma_{j l}^{\prime} \sqrt{\lambda_{l}}$.

ASV, comparable to Wricke's ecovalence, is calculated in the case of the first two main axes, as follows:

For every axis $i$ :

$$
\mathrm{ASV}_{i}=\sqrt{\left(\frac{S C_{\mathrm{ACPI}_{1}}}{S C_{\mathrm{ACPI}_{2}}} \mathrm{ACPI}_{i 1 \text { (Score })}\right)^{2}+\left(\mathrm{ACPI}_{i 2 \text { (Score })}\right)^{2}} .
$$

For every environment $j$ :

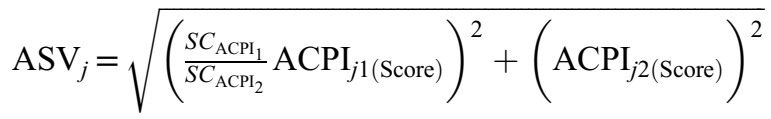

with:

$$
S C_{\mathrm{ACP} 1}=\text { axis } 1 \text { value and } S C_{\mathrm{ACP} 2}=\text { axis } 2 \text { value. }
$$

Values of selected genotypes vectors on the main axes are indicators of their stability and adaptability to different environments. The higher values, positively or negatively, are corresponding to genotypes adapted to particular conditions of the environment. However, stable genotypes in all environments present values near to zero.

\section{RESULTS}

A combined analysis of variance was carried out on the various studied parameters showed (Table 3):

- A highly significant genotype effect for the majority of parameters. The genotype effect was not significant for kernel filling duration (KFD) and the HI.

- A highly significant environment effect for measurable genotype traits, except for the heading duration, PM, and KFD.

- A highly significant $G \times E$ effect for the following parameters: $\mathrm{PH}, \mathrm{BY}$, kernel number per spike (KNS), and finally GY per $\mathrm{m}^{2}$. 
Table 3. Combined analysis (random ANOVA2): $F$-test values for all traits and sum squares values of the 25 genotypes tested at two environments over a period of 2 years 2014-2015

\begin{tabular}{lccr}
\hline & \multicolumn{3}{c}{ Values and $F$-test significance } \\
\cline { 2 - 4 } Variables & Genotype & Environment & Interaction \\
\hline Heading duration (HD) & $8.27^{* * *}$ & 0.09 & 0.06 \\
Physiological maturity (PM) & $16.44^{* * *}$ & 0.06 & 0.13 \\
Kernel filling duration (KFD) & 0.83 & 0.00 & 0.05 \\
Plant height (PH) & $177.33^{* * *}$ & $145.62^{* * *}$ & $15.10^{* * *}$ \\
Biological yield (BY) & $63.96^{* * *}$ & $1,501.90^{* * *}$ & $43.83^{* * *}$ \\
Harvest index (HI) & 1.46 & $17.97^{* * *}$ & 0.69 \\
Grain yield/ear (GYE) & $445.74^{* * *}$ & $599.98^{* * *}$ & $162.28^{* * *}$ \\
Kernel number/spike (KNS) & $88.16^{* * *}$ & $312.28^{* * *}$ & $52.58^{* * *}$ \\
Grain yield/m ${ }^{2}$ (GY) & $483.10^{* * *}$ & $2,145.46^{* * *}$ & $153.81^{* * *}$ \\
\hline
\end{tabular}

Note. ANOVA: analysis of variance.

*** Significant according to Student's $t$-test at the .01 probability level.

GY remains the basis of genotype selection. This parameter depends on genotype characteristics and environmental conditions. To identify the genotypes that highly contribute to $\mathrm{G} \times \mathrm{E}$ for $\mathrm{GY}$ per $\mathrm{m}^{2}$, decomposition of $\mathrm{G} \times \mathrm{E}$ is required. Table 4 presents the overall average yields and the different parameters of adaptability and stability of the different genotypes in the four environments.

According to the results assigned in Table 4, V2 was the most genotype that contributes to $\mathrm{G} \times \mathrm{E}$ with the highest $W_{i^{-}}$ Ecovalence (16.94\%). The same genotype is the most

Table 4. Average yield $\left(\mathrm{g} / \mathrm{m}^{2}\right)$ and values of the parameters of adaptability and stability of 25 genotypes

\begin{tabular}{|c|c|c|c|c|c|c|}
\hline Genotype & Mean grain yield $\left(\mathrm{g} / \mathrm{m}^{2}\right)$ & $b_{i}$ & $d_{i}$ & $\left(W_{i} \%\right)$ & $S_{l i}$ & ASV $\%$ axes $1-2$ \\
\hline V1 & 502.25 & 1.36 & 37.24 & 0.90 & 5.17 & 1.46 \\
\hline V2 & 430.75 & 1.07 & 198.94 & 16.94 & 11.67 & 7.75 \\
\hline V3 & 482.00 & 1.06 & 58.65 & 1.48 & 5.33 & 2.40 \\
\hline V4 & 495.42 & 0.44 & 107.16 & 5.63 & 9.17 & 4.43 \\
\hline V5 & 532.42 & 0.91 & 75.65 & 2.46 & 6.17 & 2.84 \\
\hline V6 & 293.08 & 0.48 & 29.36 & 0.99 & 1.50 & 0.11 \\
\hline V7 & 458.08 & 1.08 & 40.37 & 0.71 & 6.17 & 1.38 \\
\hline V8 & 468.75 & 0.88 & 123.72 & 6.58 & 9.67 & 5.02 \\
\hline V9 & 457.00 & 1.94 & 31.53 & 2.49 & 6.67 & 2.27 \\
\hline V10 & 463.75 & 0.75 & 62.50 & 1.81 & 6.33 & 2.54 \\
\hline V11 & 473.83 & 1.59 & 134.18 & 8.51 & 10.83 & 4.98 \\
\hline V12 & 381.58 & 2.06 & 13.97 & 2.68 & 6.17 & 1.62 \\
\hline V13 & 483.67 & 0.78 & 65.37 & 1.93 & 8.00 & 2.58 \\
\hline V14 & 440.42 & -0.19 & 101.98 & 7.73 & 12.17 & 4.25 \\
\hline V15 & 340.17 & 1.06 & 106.96 & 4.90 & 5.50 & 4.01 \\
\hline V16 & 475.08 & 0.98 & 120.72 & 6.23 & 8.83 & 4.84 \\
\hline V17 & 376.50 & 0.85 & 97.12 & 4.09 & 7.33 & 3.69 \\
\hline V18 & 415.42 & 1.84 & 75.16 & 4.06 & 8.50 & 3.59 \\
\hline V19 & 451.17 & 1.72 & 26.26 & 1.48 & 4.67 & 1.85 \\
\hline $\mathrm{V} 20$ & 481.83 & 1.95 & 31.88 & 2.52 & 8.17 & 1.04 \\
\hline THT & 572.67 & -0.01 & 51.71 & 3.50 & 4.00 & 1.08 \\
\hline HDR & 526.58 & 0.49 & 37.07 & 1.19 & 3.50 & 0.76 \\
\hline UTQ & 451.58 & 0.69 & 39.63 & 0.90 & 6.83 & 1.83 \\
\hline SLB & 261.75 & -0.16 & 106.19 & 7.94 & 1.67 & 4.96 \\
\hline VGA & 409.17 & 1.36 & 69.39 & 2.36 & 7.33 & 1.70 \\
\hline Sum & - & - & - & 100 & - & 73.00 \\
\hline Mean & 445.00 & 1.00 & 73.71 & 4.00 & 6.85 & 2.92 \\
\hline Env 1 & 363.213 & & & 19.74 & & 15.56 \\
\hline Env 2 & 436.253 & & & 40.74 & & 24.12 \\
\hline Env 3 & 492.693 & & & 21.93 & & 18.84 \\
\hline Env 4 & 487.827 & & & 17.59 & & 14.48 \\
\hline Sum & & & & 100 & & 73.00 \\
\hline
\end{tabular}

Note. THT: Tahent; HDR: Haidra; UTQ: Utique; SLB: Salammbô et VGA: Vagua; $W_{i}$ : Wricke (1962) ecovalence; $b_{i}$ : Finlay and Wilkinson (1963) regression coefficient; $d_{i}$ : Eberhart and Russell's (1966) deviation from regression parameter; $S_{l i}$ : stability index; ASV: AMMI stability value. 
Stability and adaptability concepts of bread wheat (Triticum aestivum L.)

Table 5. Mean yields and ranks of each genotype in each of the four environments

\begin{tabular}{|c|c|c|c|c|c|c|c|c|c|c|}
\hline \multirow[b]{2}{*}{ Genotype } & \multicolumn{2}{|c|}{ Environment 1} & \multicolumn{2}{|c|}{ Environment 2} & \multicolumn{2}{|c|}{ Environment 3} & \multicolumn{2}{|c|}{ Environment 4} & \multicolumn{2}{|c|}{ Total } \\
\hline & $\begin{array}{c}\text { Grain yield } \\
\left(\mathrm{g} / \mathrm{m}^{2}\right)\end{array}$ & Rank & $\begin{array}{c}\text { Grain yield } \\
\left(\mathrm{g} / \mathrm{m}^{2}\right)\end{array}$ & Rank & $\begin{array}{c}\text { Grain yield } \\
\left(\mathrm{g} / \mathrm{m}^{2}\right)\end{array}$ & Rank & $\begin{array}{c}\text { Grain yield } \\
\left(\mathrm{g} / \mathrm{m}^{2}\right)\end{array}$ & Rank & $\begin{array}{c}\text { Grain } \\
\text { yield } \\
\left(\mathrm{g} / \mathrm{m}^{2}\right) \bar{Y}_{i . .}\end{array}$ & Rank \\
\hline V1 & 410.00 & 6 & 445.33 & 13 & 585.00 & 5 & 568.66 & 3 & 502.25 & 4 \\
\hline $\mathrm{V} 2$ & 445.33 & 5 & 184.33 & 25 & 590.66 & 4 & 502.66 & 12 & 430.75 & 18 \\
\hline V3 & 367.33 & 13 & 540.33 & 5 & 532.00 & 11 & 488.33 & 15 & 482.00 & 7 \\
\hline V4 & 514.33 & 2 & 361.00 & 19 & 549.66 & 8 & 556.66 & 4 & 495.41 & 5 \\
\hline V5 & 496.00 & 3 & 436.66 & 14 & 623.66 & 2 & 573.33 & 2 & 532.41 & 2 \\
\hline V6 & 258.00 & 22 & 281.33 & 23 & 346.33 & 23 & 286.66 & 25 & 293.08 & 24 \\
\hline V7 & 377.33 & 11 & 427.00 & 15 & 480.33 & 16 & 547.66 & 5 & 458.08 & 13 \\
\hline V8 & 333.66 & 14 & 611.00 & 2 & 481.00 & 15 & 449.33 & 21 & 468.75 & 11 \\
\hline V9 & 286.66 & 20 & 469.00 & 11 & 561.66 & 7 & 510.66 & 10 & 457.00 & 14 \\
\hline V10 & 369.66 & 12 & 533.33 & 7 & 477.00 & 18 & 475.00 & 17 & 463.75 & 12 \\
\hline V11 & 389.00 & 10 & 363.33 & 18 & 683.33 & 1 & 459.66 & 20 & 473.83 & 10 \\
\hline V12 & 220.33 & 25 & 347.00 & 20 & 481.33 & 14 & 477.66 & 16 & 381.58 & 21 \\
\hline V13 & 390.00 & 9 & 548.66 & 4 & 528.33 & 12 & 467.66 & 19 & 483.66 & 6 \\
\hline V14 & 406.33 & 7 & 561.00 & 3 & 426.66 & 20 & 367.66 & 23 & 440.41 & 17 \\
\hline V15 & 283.66 & 21 & 253.00 & 24 & 328.66 & 24 & 495.33 & 14 & 340.16 & 23 \\
\hline V16 & 332.33 & 15 & 613.66 & 1 & 479.66 & 17 & 474.66 & 18 & 475.08 & 9 \\
\hline V17 & 326.33 & 16 & 316.00 & 21 & 347.00 & 22 & 516.66 & 9 & 376.50 & 22 \\
\hline V18 & 230.33 & 24 & 483.33 & 10 & 508.66 & 13 & 439.33 & 22 & 415.41 & 19 \\
\hline V19 & 304.00 & 18 & 454.33 & 12 & 549.00 & 9 & 497.33 & 13 & 451.16 & 16 \\
\hline V20 & 309.66 & 17 & 493.33 & 9 & 545.33 & 10 & 579.00 & 1 & 481.83 & 8 \\
\hline THT & 591.66 & 1 & 533.00 & 8 & 623.00 & 3 & 543.00 & 6 & 572.66 & 1 \\
\hline HDR & 481.33 & 4 & 537.33 & 6 & 580.00 & 6 & 507.66 & 11 & 526.58 & 3 \\
\hline UTQ & 404.33 & 8 & 421.00 & 16 & 458.00 & 19 & 523.00 & 8 & 451.58 & 15 \\
\hline SLB & 256.00 & 23 & 298.00 & 22 & 144.00 & 25 & 349.00 & 24 & 261.75 & 25 \\
\hline VGA & 296.66 & 19 & 394.00 & 17 & 407.00 & 21 & 539.00 & 7 & 409.16 & 20 \\
\hline$\overline{\mathrm{Y}}_{. j}$ & 363.21 & & 436.25 & & 492.69 & & 487.83 & & $\begin{array}{c}\bar{Y} \\
444.99\end{array}$ & \\
\hline$x_{j}$ & -81.784 & & -8.744 & & 47.696 & & 42.83 & & & \\
\hline
\end{tabular}

Note. THT: Tahent; HDR: Haidra; UTQ: Utique; SLB: Salammbô; VGA: Vagua.

unstable according to stability index, namely $S_{l i}(11.67)$ and ASV (7.75\%) (Table 4). The average yields and ranks occupied by this genotype in the different environments confirm its instability. Indeed, the genotype V2, which occupies the fourth position in environment 3 (E3), moves to the 25th and last position in E2 (Table 5). According to adaptability parameter materialized by the joint regression coefficient $b_{i}$ (1.07), V2 can be considered appropriate for all environments. However, standard error $d_{i}$ associated with highest regression coefficient (198.94) define the instability of this genotype, which is already confirmed by $S_{l i}$ and ASV. Other genotypes V8, V11, V14, V16, and Salammbô were lowly stable and highly contribute to the sum squares of $\mathrm{G} \times \mathrm{E}$.

Since the objective of the breeder is to identify the best performing genotypes, adapted (general or specific adaptation) and stable, only genotypes with a higher GY than the overall average of all genotypes in all environments will be considered. Based on Fig. 1, five groups of genotypes are distinguished according their general or specific adaptability:

- Specially adapted to favorable environments: V9, V19, V12, V18, and V20

- Specially adapted to unfavorable environments: Tahent, V14, and Salammbô
- Well adapted to all environments: V1, V3, V4, V5, V11, V13, V16, and Haidra

- Poorly adapted to all environments: V15, V17, and V6

- Medium stability to environment: Vaga, V2, V7, V8, Utique, and V10

Figures 2-5 rank the studied genotypes according to their average performance and stability index $\left(d_{i}, \mathrm{~W}_{\mathrm{i}}, S_{l i}\right.$, and ASV\%). The high performance and stable genotypes are placed on the right side of the overall average yield line and below the average value of each stability index.

Table 6 groups the genotypes that are considered efficient according to their mode of adaptability and their stability for each of the three used indices of stability $\left(d_{i}, S_{l}\right.$, and ASV\%).

Figure 6 shows the projection of genotypes and environments according to their vectors on the first two main axes from the AMMI analysis. According to $\mathrm{G} \times \mathrm{E}$ analysis method, the genotypes closest to the center are the most stable and on the contrary the nearest genotype to a given environment indicates their highly interactivity.

\section{DISCUSSION}

The phenotype of an individual is controlled by its genotype, the environment, and any interactions between 


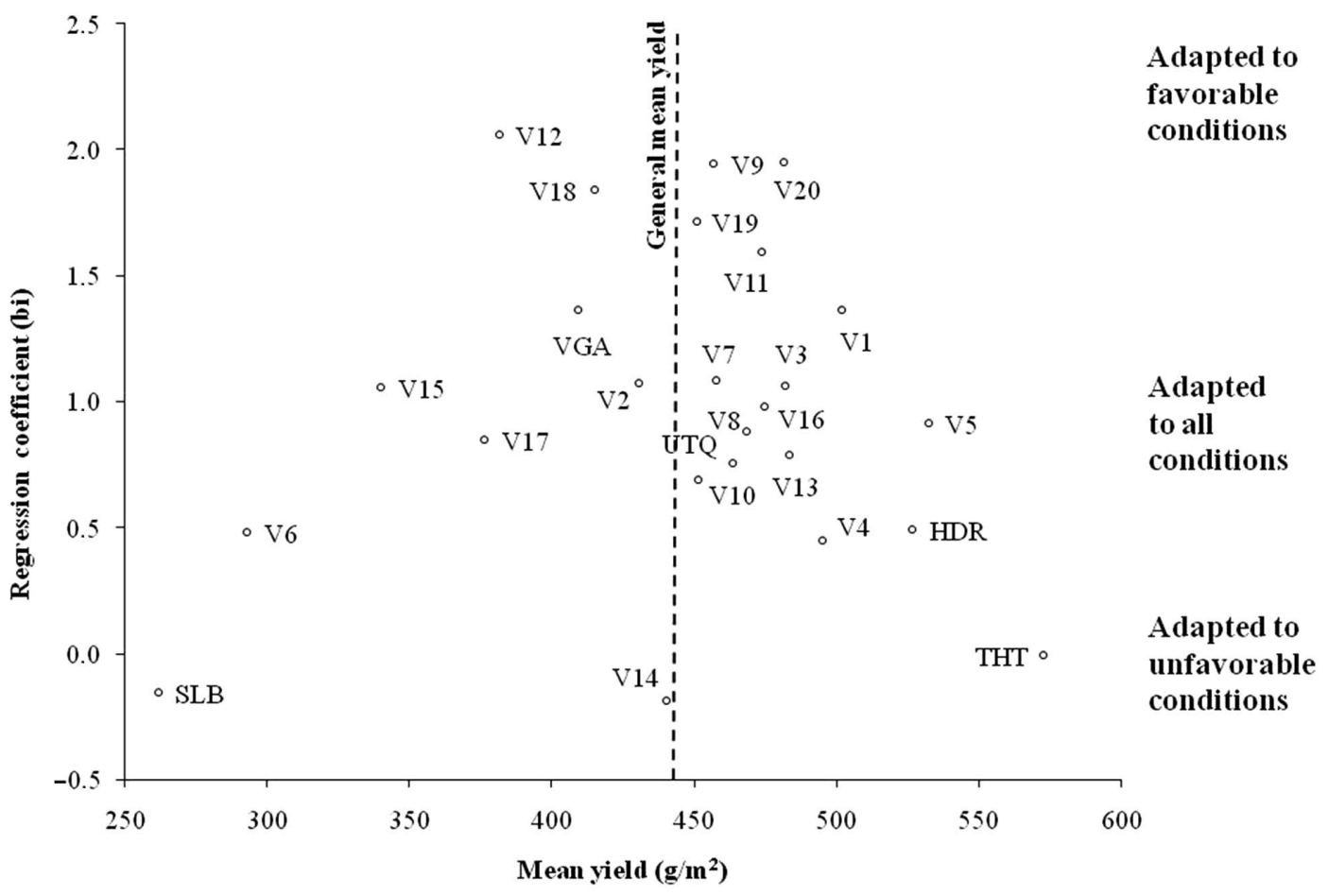

Fig. 1. Generalized interpretation of the genotypic pattern obtained when genotypic regression coefficients $\left(b_{i}\right)$ are plotted against genotypic mean, adapted from Finlay and Wilkinson (1963). Note. THT: Tahent; HDR: Haidra; UTQ: Utique; SLB: Salammbô; VGA: Vagua

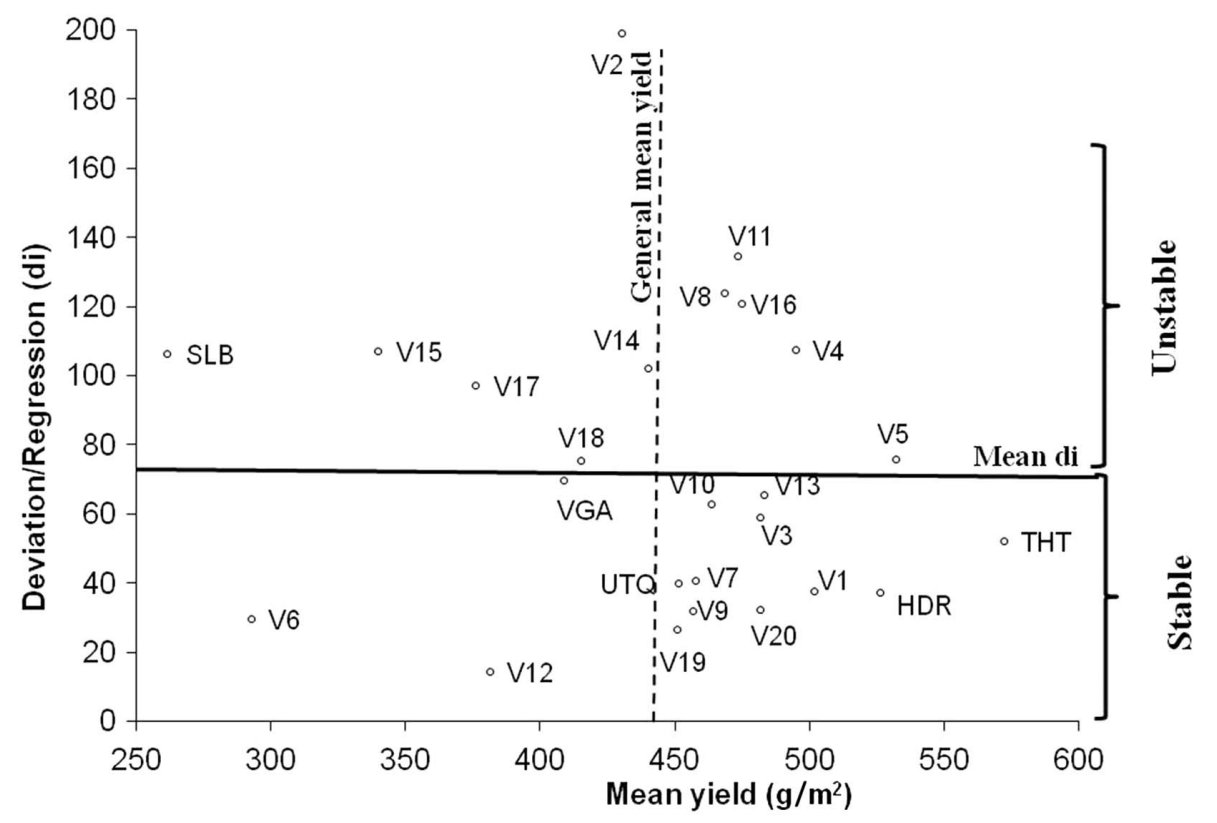

Fig. 2. Distribution of genotypes tested according to regression deviation $\left(d_{i}\right)$. Note. THT: Tahent; HDR: Haidra; UTQ: Utique; SLB: Salammbô; VGA: Vagua

genotype and environment $(\mathrm{G} \times \mathrm{E}$ interactions or $\mathrm{G} \times \mathrm{E})$. Such interactions are said to exist when the comparative performances of genotypes vary according to the environment (Li et al., 2017). The performance of one genotype that is superior in one environment might be inferior in another environment (de Jong, 1990; Falconer \& Mackay, 1996). The increase in biomass was particularly associated with the presence of the translocation "1BL-1RS" (Villareal et al., 1998) and the translocation "7DL-7Ag" (Reynolds et al., 2001). As for biomass, it contributes positively to the increase in yield (Donmez et al., 2001; Shearman et al., 2005).

According to Finlay and Wilkinson (1963), the mean GY of genotypes across all cropping environments and regression coefficients $\left(b_{i}\right)$ are important indicators of genotypic adaptation. Regression coefficients approximating to 1.0 indicate average stability, but must always be associated and interpreted with the genotype mean yield to determine 


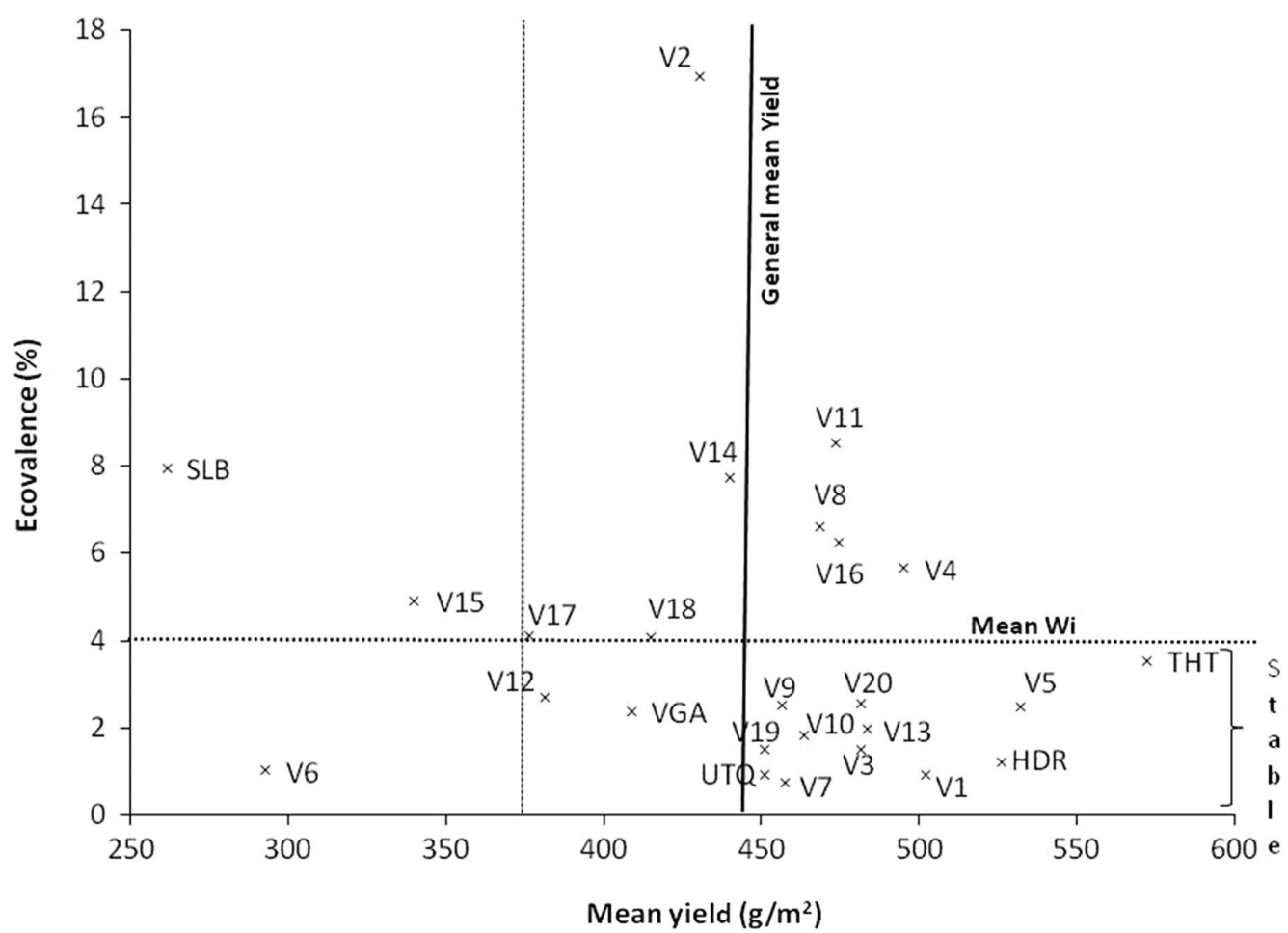

Fig. 3. Distribution of genotypes tested according to Wricke Ecovalence $\left(W_{i}\right)$. Note. THT: Tahent; HDR: Haidra; UTQ: Utique; SLB: Salammbô; VGA: Vagua

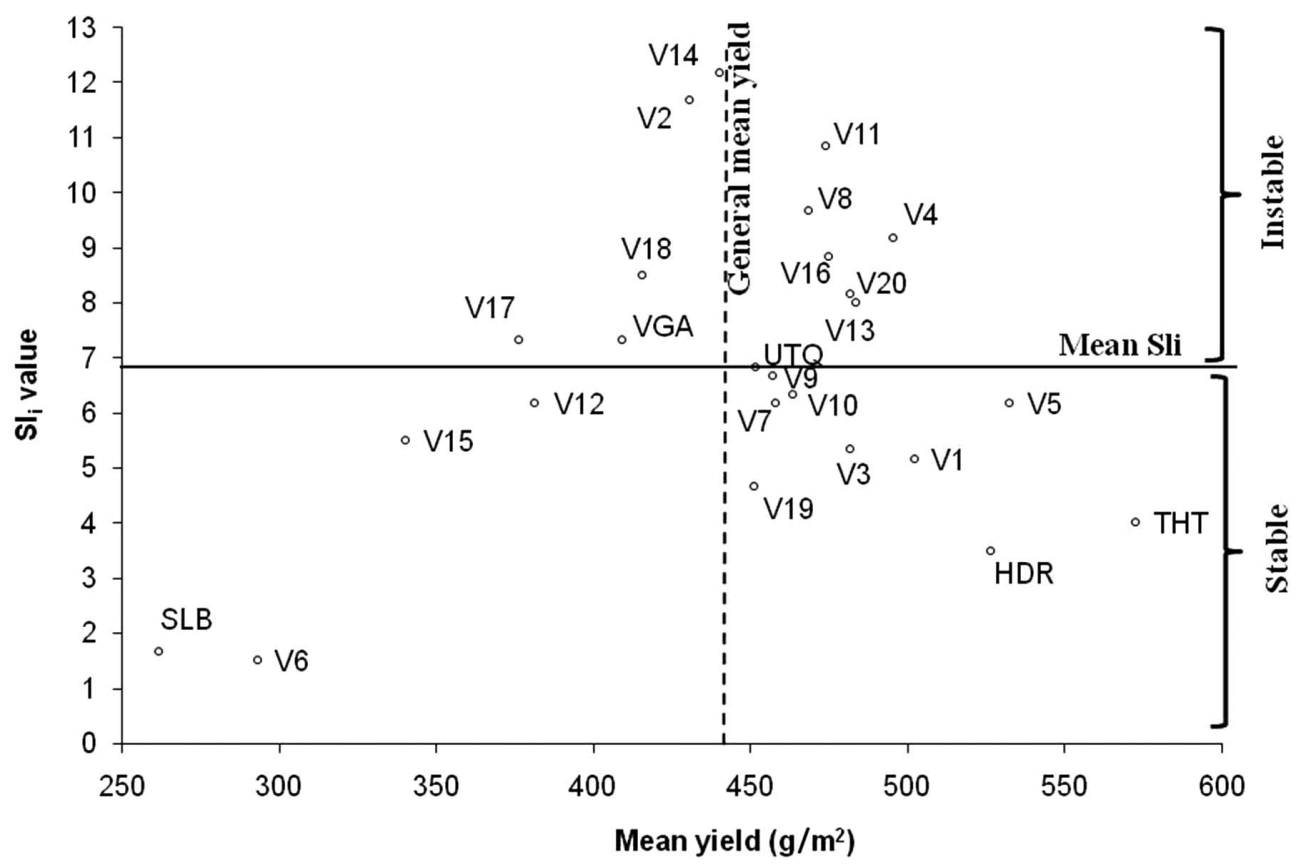

Fig. 4. Distribution of genotypes tested according to Hühn stability $\left(S_{l i}\right)$. Note. THT: Tahent; HDR: Haidra; UTQ: Utique; SLB: Salammbô; VGA: Vagua

its adaptability. Regression coefficients decreasing below 1.0 provide a measure of greater resistance to environmental change, having above average stability but showing more specific adapted to low yielding environments. Crossa (1990) reported that in the case of significant qualitative interactions, genotype groups should be recommended only for specific environments. This is faithful with our results that showed three classes according to their best performance in specific environments. Adaptability coefficient established by joint regression $b_{i}$ (Fig. 2) allowed the classification of high production lines and varieties into three groups: (a) specific adaptation to favorable conditions such as V20, V9, and V19 [General mean yield $(\mathrm{GMY})=$ $481.33,457$, and $451.17 \mathrm{~g} / \mathrm{m}^{2}$, respectively]; (b) adaptation to 


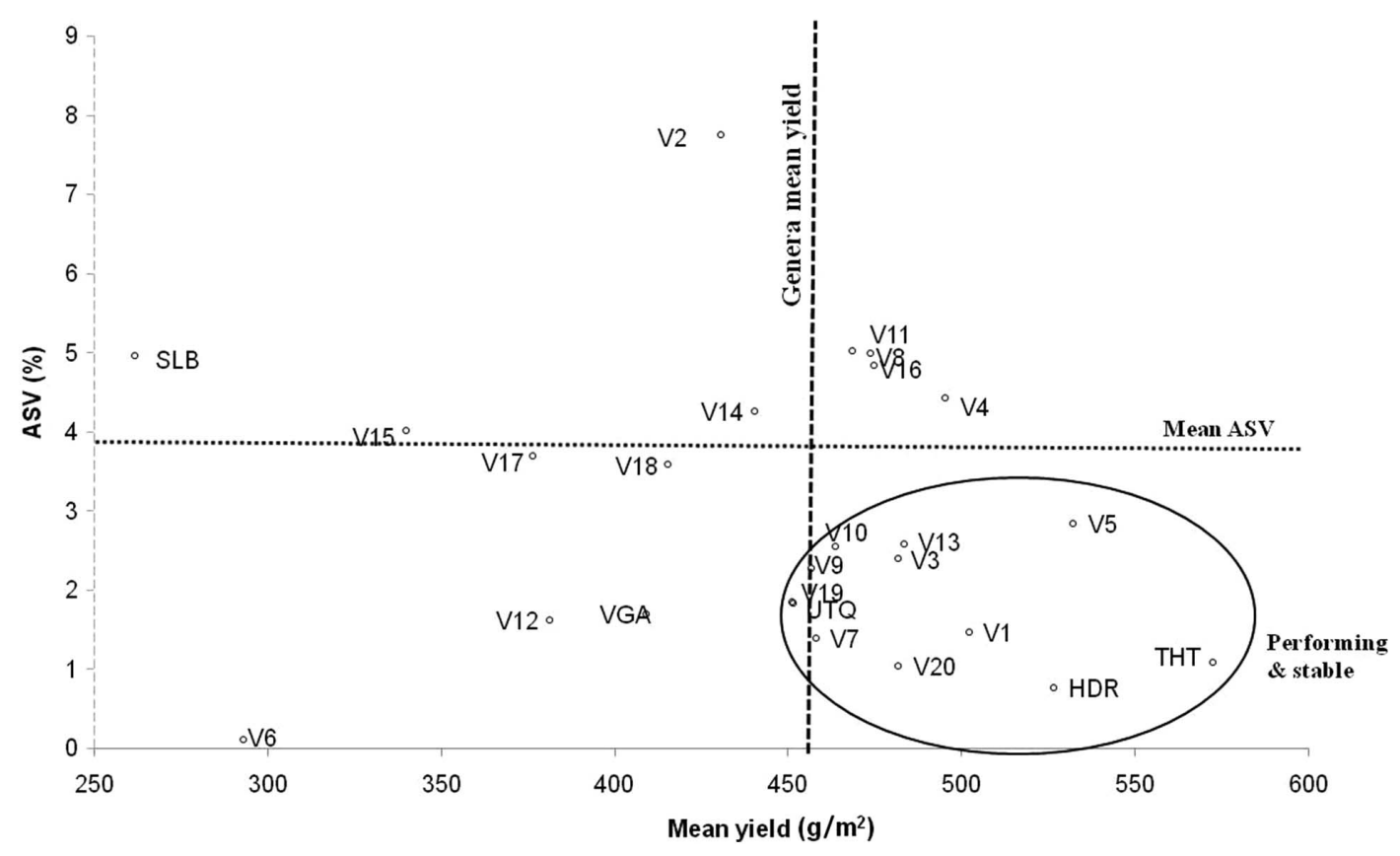

Fig. 5. Distribution of genotypes tested according to AMMI analysis. Note. THT: Tahent; HDR: Haidra; UTQ: Utique; SLB: Salammbô; VGA: Vagua

Table 6. Summary table of genotypes adapted to different environmental conditions according to the different used concepts of stability

\begin{tabular}{|c|c|c|c|c|c|}
\hline \multirow[b]{2}{*}{ Adaptability } & \multirow[b]{2}{*}{ Variety } & \multicolumn{4}{|c|}{ Stability } \\
\hline & & $d_{i}$ & $S_{l i}$ & ASV & $\begin{array}{c}3 \\
\text { parameters }\end{array}$ \\
\hline \multirow{3}{*}{$\begin{array}{l}\text { Favorable } \\
\text { environment }\end{array}$} & V9 & & + & + & \\
\hline & V19 & + & + & + & + \\
\hline & V20 & + & + & + & + \\
\hline $\begin{array}{l}\text { Unfavorable } \\
\text { environment }\end{array}$ & THT & + & + & + & + \\
\hline \multirow[t]{11}{*}{ All environments } & V1 & + & + & + & + \\
\hline & V3 & & + & + & \\
\hline & V4 & & + & + & \\
\hline & V5 & + & + & + & + \\
\hline & V7 & + & + & + & + \\
\hline & V8 & & + & + & \\
\hline & V10 & + & + & + & + \\
\hline & V11 & & + & + & \\
\hline & V13 & + & + & + & + \\
\hline & UTQ & + & + & + & + \\
\hline & HDR & + & + & + & + \\
\hline
\end{tabular}

Note. THT: Tahent; HDR: Haidra; UTQ: Utique.

unfavorable conditions such as Tahent $\left(\mathrm{GMY}=572.66 \mathrm{~g} / \mathrm{m}^{2}\right)$, and (c) wide adaptation to all conditions (majority with GMY > $458 \mathrm{~g} / \mathrm{m}^{2}$ : V1, V3, V4, V5, V7, V8, V10, V11, V13, Utique, and Haidra). Considering climate change, the most interesting genotype is Tahent. This variety contains the translocation 1BL-1RS (Carver \& Rayburn, 1994). Genotypes with 1BL-1RS translocation showed an increase in overall mean yield by $9 \%-10 \%$ associated with an improvement in biomass to $11 \%-12 \%$ as compared to control genotypes (Carver \& Rayburn, 1994). Li et al. (2014) reported that $1 \mathrm{BL}-1 \mathrm{RS}$ alleles from $\mathrm{BW}$ contributed to improved resistance to biotic and abiotic stresses, increased number of ears, KNS, kernel weight, and yield potential. V5 line (wide adaptation) also contains this translocation 1BL-1RS. Measures deviations (residuals) from observations around the regression line " $S_{d i}$ " adopted by Eberhart and Russell (1966) to measure stability. It measures deviations (residuals) from observations around the regression line (joint regression) and gives an idea of the degree of significance of the regression result. The results obtained showed again that Tahent is the most stable genotype with Haidra, V1, V13, V3, V20, V10, V7, V9, and V19.

The results showed that the most stable germoplasms with high yield were Tahent and V5 (containing 1BL-1RS translocation), Haidra, V1, V13, V20, V3, V10, V9, V7, V19, and Utique. Tahent, V1, V3, V10, V13, and Haidra genotypes were then adapted and stable according to $b_{i}$ and $d_{i}$. Wricke $\left(W_{i}\right)$ provides a clear and easy idea about genotype stability, which has shown that V2 and V11 lines were the most unstable; they hold $25 \%$ of the total variation and have shown the most important variation in the environment E4 compared to E3 (Table 5), making them the most demanding in terms of water, showing significant GY improvement during favorable years in Oued Beja area (subhumid).

The results obtained with Hühn stability $\left(S_{l i}\right)$ confirm that Tahent, V5, Haidra, V1, V3, and V10 were again stable according to $b_{i}$ and $d_{i}$, but new genotypes (V9, V19, and V7) arise stable. Similar results to $S_{l i}$ were obtained with ASV methods (Table 6). ASV can be useful to rank genotypes. This method also ascribes the sources of instability to different principal components, which in turn can be clearly explained in terms of environmental and/or biological factor(s). 


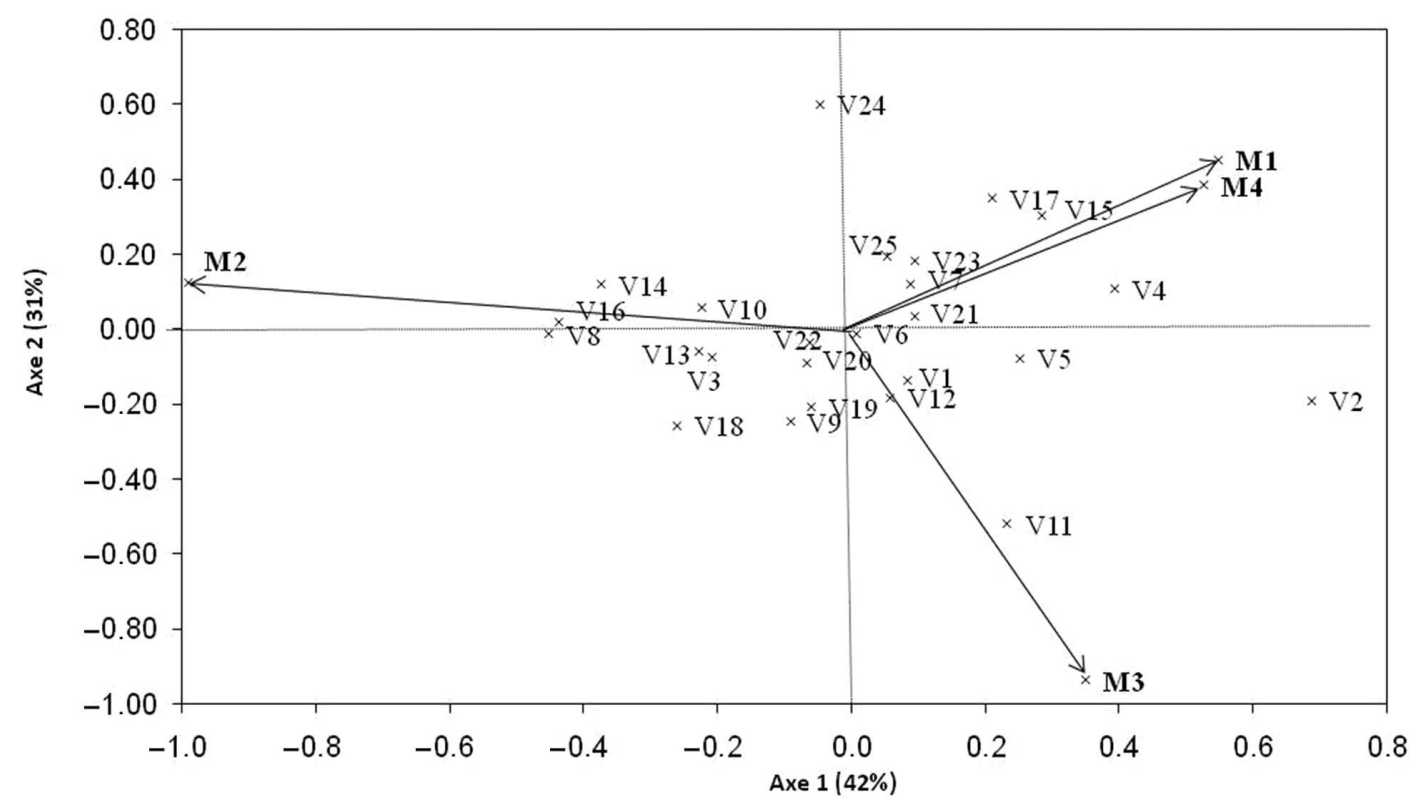

Fig. 6. Biplot of the first axis of the principal component analysis of the interaction (ACPI1) and the second axis (ACPI2) for the 25 bread wheat genotypes

\section{CONCLUSION FOR FUTURE BIOLOGY}

Genotype $\times$ environment interaction has been an important topic among plant breeders and agronomists engaged in performance testing, which leads to bias in the estimates of gene effects for various characters that are influenced by the environment variations such as GY. The use of multitude biometric methods as decomposition of $\mathrm{G} \times \mathrm{E}$ for adaptability or to analyze GY stability of wheat genotypes revealed that Tahent variety and V20 were the most stable in yield according to the used methods. Such performance is a desirable quality of cultivars, especially in countries like Tunisia, where environmental variations are very important and unpredictable. Efforts to improve in such environments should put more emphasis on genotypes such as V20. In addition, genotypes with low phenotypic stability must be discarded before being released. The use of appropriate biometric techniques is needed to identify the most suitable, responsive, and stable genotypes in the final stages of the breeding programs.

Acknowledgments: The authors would like to thank the LGC chief (INRAT) and the director of CRRGC for offering facilities to carry out this research. They would also like to thank Ms. Z. Medini, A. Aouadi, J. Nasri, S. Ouhichi, and S. Becherif for their technical support.

\section{Ethical Statement: None.}

Funding Statement: This research did not receive funding from any agency.

Data Accessibility: The data that support the findings of this study are available from the authors SA and $\mathrm{BH}$ upon reasonable request.
Competing Interests: The authors declare no competing interests.

Authors' Contributions: SA and BH contributed equally to this work, suggested the research point, carried out experiments, and wrote the main manuscript. ST performed statistical analysis. SR and FS critically edited the manuscript. SA, BH, and ST approved the final version of the manuscript to be published.

\section{REFERENCES}

Brancourt-Hulmel, M., Lecomte, C., Meynard, J. M. (1997) Points de repères dans l'analyse de la stabilité et de l'interaction génotype $\mathrm{x}$ milieu en amélioration des plantes [Guiding marks on stability and genotype-environment interaction analysis in plant breeding]. Agronomie 17, 219-246.

Carver, B. F., Rayburn, A. L. (1994) Comparison of related wheat stocks possessing 1B or 1Rs. 1Bl. Chromosomes: agronomic performance. Crop Sci. 34, 1505-1510.

Chamekh, Z., Fraj, N., Karmous, C., Ayadi, S., Sahli, A., Hammami, Z., Belhaj, M., Benaissa, N. N., Trifa, Y., Slim-Amara, H. (2015) Stability analysis of yield component traits in 25 durum wheat (Triticum durum Desf.) genotypes under contrasting irrigation water salinity. Agricult. Water Man $152,1-6$

Crossa, J. (1990) Statistical analysis of multi-location trials. $A d v$. Agron. 44, 55-85.

de Jong, G. (1990) Genotype-by-environment interaction and the genetic covariance between environments: multilocus genetics. Genetica 81, 171-177.

Donmez, E., Sears, R. G., Shroyer, J. P., Paulsen, G. M. (2001) Genetic gain in yield attributes of winter wheat in the Great Plains. Crop Sci. 4, 1412-1419. 
Eberhart, S. A., Russell, W. A. (1966) Stability parameters for comparing varieties. Crop Sci. 6, 36-40.

Falconer, D. S., Mackay, T. F. C. (1996) Introduction to Quantitative Genetics (4th ed.). Longman, Harlow, Essex.

Fikere, M., Bing, D. J., Tadesse, T., Ayana, A. (2014) Comparison of biometrical methods to describe yield stability in field Pea (Pisum sativum L.) under south eastern Ethiopian conditions. Afr. J. Agric. Res. 9(33), 2574-2583.

Finlay, W., Wilkinson, G. N. (1963) The analysis of adaptation in a plant breeding program. Aust. J. Agric. Res. 14, 742-754.

Khan, A. J., Azam, F., Ali, A., Tariq, M., Amin, M., Muhammad, T. (2007) Wide and specific adaptation of bread wheat inbred lines for yield under rainfed conditions. Pak. J. Bot. $39,67-71$.

Li, J., Wan, H., Yang, W. (2014) Synthetic hexaploid wheat enhances variation and adaptive evolution of bread wheat in breeding processes. J. Syst. Evol. 52, 735-742.

Li, Y., Suontama, M., Burdon, R. D., Dungey, H. S. (2017) Genotype by environment interactions in forest tree breeding: review of methodology and perspectives on research and application. Tree Genet. Genome 13, 60.

Loss, S. P., Siddique, K. H. M. (1994) Morphological and physiological traits associated with wheat yield increases in Mediterranean environments. Adv. Agron. 52, 229-276.

Nachit, M. M., Nachit, G., Ketata, H., Jr., Gauch, H. G., Zobel, R. W. (1992) Use of AMMI and linear regression models to analyze genotype-environment interaction in durum wheat. Theor. Appl. Genet. 83, 597-601.

Preece, D. (1997) Statistical methods for plant variety evaluation, eds R. A. Kempton \& P. N. Fox. xii 191 pp.
London: Chapman \& Hall (1997). J. Agric. Sci. 128(4), 499-501.

Purchase, J. L. (1997) Parametric Stability to Describe $G \times E$ Interactions in Yield Stability in Winter Wheat ( $\mathrm{PhD}$ thesis). Department of Agronomy, Faculty of Agriculture, Orange Free State, Bloemfontein, South Africa.

Reynolds, M. R., Calderini, D. F., Condon, A. G., Rajaram, S. (2001) Physiological basis of gains in wheat associated with the LR 19 translocation from Agropyron elongatum. Euphytica 119, 137-141.

Romagosa, I., Fox, P. N. (1993) Genotype $\times$ environment interaction and adaptation. In: Hayward, M. D., Bosemark, N. O., Romagosa, I. (eds.) Plant Breeding: Principles and Prospects. Chapman and Hall, London, pp. 373-390.

SAS Institute Inc. (2004) SAS/STAT 9.1 Users' Guide. SAS Institute Inc., Cary, NC.

Shearman, V. J., Sylvester-Bradley, R., Scott, R. K., Foulkes, M. J. (2005) Physiological processes associated with wheat yield progress in the UK. Crop Sci. 45, 175-185.

Subira, J., Alvaro, F., Garcia del Moral, F. (2015) Breeding effects on the cultivars $\times$ environment interaction of durum wheat yield. Eur. J. Agron. 68, 78-88.

Villareal, R. L., Banuelos, O., Mujeeb-kazi, A., Rajaram, S. (1998) Agronomic performance of chromosomes $1 \mathrm{~B}$ and 1BL.1RS near-isolines in the spring bread wheat Seri M82. Euphytica 103, 195-202.

Wricke, G. (1962) Evaluation method for recording ecological differences in field trials. Z Pflanzenzücht 47, 92-96.

Zadoks, J. C., Chang, T. T., Konzak, C. F. (1974) A decimal code for the growth stages of cereals. Weed Res. 14, 415-421. 